\title{
Isogonals of a Triangle.
}

By J. S. Mackay, M.A., LI.D.

Definirios. - If two angles have the same vertex and the same biscctor, the sides of either angle are isogonal* to each other with respect to the other angle.

Thus the isogronal of $A P$ with respect to $\angle B A C$ is the image of $\mathrm{AP}$ in the bisector of $\angle \mathrm{BAC}$. It is indifferent whether the bisector of the interior $\angle \mathrm{BAC}$ be taken, or the bisector of the angle adjacent to it; the isogonal of $A P$ remains the same.

It follows from the definition that

(1) The internal and the external bisectors of $\angle \mathrm{BAC}$ are their own isogonals.

(2) The line joining the orthocentre of a triangle to any vertex is isogonal to the line joining the circumcentre to that vertex.

(3) Any internal median of a triangle is isogonal to the corresponding symmedian.

(4) The tangents to the circumcircle of $\mathrm{ABC}$ at $\mathrm{A}, \mathrm{B}, \mathrm{C}$ are isogonal to the external medians.

[The external medians are the parallels to the sides of a triangle drawn through the opposite vertices.

The reason for the giving of this name will be fuund in the Proccedings of the Ealinlurgh Mathematical Socicty, Vol. I., p. 16 (1894).]

* This terminology was propused by Mr G. de Longchamps in his Journal che Mathénatiques Élćmentaires, 2nd series, Vol. V., p. 245 (1886). 
$\$ 1$.

(a) If $P, Q$ be any two points taken on a pair of lines isogonal. with respect to angle $B A C$, the distances of $P$ from $A B, A C$ are inversely proportional* to those of $Q$ from $A B, A C$.

\section{Figure 29.}

If the quadrilateral $\mathrm{AQ}_{2} \mathrm{QQ}_{1}$ be revolved through two right angles round the bisector of $\angle \mathrm{B}$ as an axis, it will become homothetic to the quadrilateral $\mathrm{AP}_{1} \mathrm{PP}_{2}$; therefore

$$
P P_{1}: P P_{2}=Q_{2}: Q_{1}
$$

$\left(a^{\prime}\right)$ If $P, Q$ be any tuo points and if the distances of $P$ from $A B, A C$ be inversely proportional to those of $Q$ from $A B, A C$, then $A P, A Q$ are isogonal with respect to $\angle B A C$.

This may be proved indirectly.

(1) The points $P_{1} Q_{1} \quad Q_{2} P_{2}$ are concyclic $\dagger$

Since $P_{1} P_{2} \quad Q_{1} Q_{2}$ are antiparallel with respect to $\angle B A C$; therefore $\begin{array}{llllll}P_{1} & P_{2} & Q_{1} & Q_{2} & \text { are concyclic. }\end{array}$

(2) The centre of the circle $P_{1} Q_{1} Q_{2} P_{2}$ is the mid point of $P Q$.

For the perpendicular to $P_{1} Q_{1}$ at its mid point goes through the centre of the circle; and this perpendicular bisects $P Q$.

So does the perpendicular to $P_{2} Q_{2}$ at its mid point.

(3) $P_{1} P_{2}$ is perpendicular to $4 Q$

$$
\text { and } Q_{1} Q_{2}, \quad, \quad, A P \text {. }
$$

- Sir James Ivory in Leybourn's Mathematical Rcpository, new series, Vol. I., Part II., p. 19 (1806). The mode of proof is due to Professor Neuberg. See his excellent memoir on the Recent Geometry of the Triangle in Rouché and Conberousse's Traité dc Géométrie, First Part, p. 438 (1891).

+ This and the two following theorems are due to Steiner. See Gergonne's Annales, XIX., 37-64 (1828), or Steiner's Gesammelte Werke, I., 191-210 (1881). The proof given of (1) is Professor Neuberg's. See the reference in the prceeding note, 
For $\mathrm{AP}$ is a diameter of the circumcircle of $\mathrm{AP}_{1} \mathrm{P}_{2}$; therefore the isogonal of $\mathrm{AP}$ with respect to $\angle \mathrm{P}_{1} A \mathrm{P}_{2}$ is the perpendicular * from $A$ to $P_{1} P_{2}$

(4) The circumcentre of either of the triangles $A_{1} P_{2} \quad A Q_{1} Q_{2}$ and the orthocentre of the other are collinear with the point $A$.

(5) Triangle, $P P_{1} P_{2}$ is inversely similar + to $Q Q_{2} Q_{1}$.

This follows from the demonstration of $\$ 1$; or it may be thus proved :

Similarly

$$
\angle \mathrm{PP}_{1} \mathrm{P}_{2}=\angle \mathrm{PAP}_{2}=\angle \mathrm{QAQ}_{1}=\angle \mathrm{QQ}_{2} \mathrm{Q}_{1} .
$$

$$
\angle P P_{2} P_{3}=\angle Q Q_{1} Q_{2}
$$

(6) If $P P_{1} Q Q_{2}$ neet at $D$

and $P P_{2} Q Q_{1} \quad, " E$,

then $A D, A E$ are isogonals with respect to $\angle B A C$.

Figure 30.

Join $\mathrm{P}_{1} \mathrm{Q}_{2} \mathrm{P}_{2} \mathrm{Q}_{1}$.

Since $P_{1} Q_{1} P_{2} Q_{2}$ are concyclic,

therefore

$$
\angle A Q_{2} P_{1}=\angle A Q_{1} P_{2}
$$

therefore their complements are equal

that is

Similarly

therefore triangles

therefore

Now triangles

therefore

Hence

and $\angle P_{1} Q_{2} D=\angle P_{2} Q_{1} E$.

$\angle \mathrm{Q}_{2} \mathrm{P}_{1} \mathrm{D}=\angle \mathrm{Q}_{1} \mathrm{P}_{2} \mathrm{E}$;

$P_{1} Q_{2} D, P_{2} Q_{1} E$ are similar;

$P_{1} Q_{2}: P_{1} D=P_{2} Q_{1}: P_{2} E$.

$A P_{1} Q_{2}, A_{2} Q_{1}$ are similar ; $A P_{1}: P_{1} Q_{2}=A_{2}: P_{2} Q_{1}$. $A P_{1}: P_{1} D=A P_{2}: P_{2} E$

$$
-P_{1} A D=\angle P_{2} A E \text {. }
$$

The same result might be arrived at by revolving the quadrilateral $A Q_{2} Q_{Q}$ through two right angles round the bisector of $\angle$ BAC.

* This mode of proof is given by Professor Fuhrmann in his Synthetische Bcrecise planimctrischer. Saitzc, p. 93 (1890).

t Sre Irory's paper already cited, p. 20. 
(a) If $A B C$ be a triangle, and if $A P, A Q$ be isogonal with respect to $A$, then *

$$
B P \cdot B Q: C P \cdot C Q=A B^{2}: A C^{2}
$$

\section{Figure 31.}

About $\mathrm{APQ}$ circumscribe a circle, cutting $\mathrm{AB}, \mathrm{AC}$ in $\mathrm{F}, \mathrm{E}$; join $\mathrm{FE}$.

$\begin{array}{ll}\quad \text { Because } & \quad \angle \mathrm{BAP}=\angle \mathrm{CAQ} \\ \text { therefore } & \text { arc FP }=\text { arc } \mathrm{EQ} \\ \text { therefore } & \mathrm{FE} \text { is parallel to } \mathrm{BC} \\ \text { therefore } & \mathrm{AB}: \mathrm{BB}=\mathrm{AC}: \mathrm{CE} \\ \text { therefore } & \mathrm{AB}^{2}: \mathrm{AB} \cdot \mathrm{BF}=\mathrm{AC} \mathrm{C}^{2}: \mathrm{AC} \cdot \mathrm{CE} \\ \text { therefore } & \mathrm{AB}^{2}: \mathrm{BP} \cdot \mathrm{BQ}=\mathrm{AC}: \mathrm{CP} \cdot \mathrm{CQ}\end{array}$

A second demonstration will be found in C. Adams's Die merkwürdigsten Eigenschaften des geradlinigen Dreiecks, p. 1 (1846), and a third in Professor Fuhrmann's Synthetische Beweise, p. $94(1890)$.

(a') If $A B C$ be a triangle and $B C$ be divided at $P$ and $Q$ so that

$$
B P \cdot B Q: C P^{\cdot} C Q=A B^{2}: A C^{2}
$$

then $\dagger A P, A Q$ are isogonals with respert to $A$.

This may be proved indirectly.

(1) If $\mathrm{AQ}$ be the internal or the external median from $\mathrm{A}$, then $\mathrm{BQ}=\mathrm{CQ}$, and the theorem becomes

$$
\mathrm{BP}: \mathrm{CP}=\mathrm{AB}^{2}: \mathrm{AC}^{2} \text {. }
$$

\footnotetext{
* Pappus's Mathematical Collection, VI. 12. The same theorem differently stated is more than onee proved in Book VII. annong the lemmas which Pappus gives for Apollonius's treatise on Deterninate Section. The proof in the text is taken from Pappus.

† In Pappus's Mathematical Collection, VI. 13, there is proved the theorem :

$$
\text { If } \mathrm{BP} \cdot \mathrm{BQ}: \mathrm{CP} \cdot \mathrm{CQ}>\mathrm{AB}^{2}: \mathrm{AC} \cdot
$$

then

$$
\angle \mathrm{BAP}>\angle \mathrm{CAQ} \text {. }
$$

$\mp$ Adams (see the reference to him on this page) gives (1)-(4), (6), (8). His proof of (4) is different from that in the text.
} 
(2) If $A Q$ be the internal or the external median from $A$ and $\angle B A C$ be right, then $A P$ is perpendicular to $B C$.

Figuras 32, 33.

Since $\quad \angle \mathrm{ACP}=\angle \mathrm{CAQ}=\angle \mathrm{BAP}$

therefore $\angle \mathrm{ACB}+\angle \mathrm{CAP}=\angle \mathrm{BAP}+\angle \mathrm{CAP}$

$=\mathrm{a}$ right angle.

(3) If $\mathrm{AP}$ and $\mathrm{AQ}$ coincide, then $\mathrm{AP}$ is either the internal or the external bisector of $-\mathrm{A}$, and the theorem becomes

or

$$
\begin{aligned}
& \mathrm{BP}^{2}: \mathrm{CP}^{2}=\mathrm{AB}^{2}: \mathrm{AC}^{2} \\
& \mathrm{BP}: \mathrm{CP}=\mathrm{AB}: \mathrm{AC}
\end{aligned}
$$

a known result, namely, Euclid VI. 3, or the cognate theorem.

$$
B P \cdot C P: B Q \cdot C Q=A P^{n}: A Q^{2}
$$

This follows from the theorem of $\$ 2$ by considering $A P Q$ as the triangle and $\mathrm{AB}, \mathrm{AC}$ as the isogonals.

(5) If $A P, A Q$ which are isogonal with respect to $\angle B A C$ meet the circumcircle of $A B C$ in $R, S$, then $A P \cdot A S=A Q \cdot A R$.

\section{Figure 34.}

For triangles $A C R, A Q B$ are similar therefore $\quad A Q \cdot A R=A B \cdot A C$. Similarly $\quad \mathrm{AP} \cdot \mathrm{AS}=\mathrm{AB} \cdot \mathbf{A C}$.

(6) RS is parallel to $\mathrm{BC}$.

(7) The distances from the mid point of any side of a triangle to the points where two isogonals from the opposite vertex meet the circumcircle are equal.*

For the perpendicular which bisects BC bisects RS.

* Mr Emile Vigarié in the Journal dc Mathématiques Élémentaires, 2nd series, IV. 59 (1885). 
(8) If APR becomes the diameter of the circumcircle ABC then $\mathrm{AQ}$ becomes perpendicular to $\mathrm{BC}$, and

$$
\mathrm{AQ} \cdot \mathrm{AR}=\mathrm{AB} \cdot \mathrm{AC} \text {, }
$$

a theorem of Brahmegupta's.

See Chasles's Aperru, 2nd ed., pp. 420-447.

(9) If AP, AQ coincide, then AP becomes either the internal or the external bisector of $\angle A$.

Hence in the first case

$$
\begin{aligned}
\mathrm{AB} \cdot \mathrm{AC} & =\mathrm{AP} \cdot \mathrm{AS} \\
& =\mathrm{AP} \cdot \mathrm{PS}+\mathrm{AP^{ \prime \prime }} \\
& =\mathrm{BP} \cdot \mathrm{PC}+\mathrm{AP}^{2}
\end{aligned}
$$

and in the second case

$$
\begin{aligned}
\mathrm{AB} A C & =\mathrm{AP} \cdot \mathrm{AS} \\
& =\mathrm{AP} \cdot \mathrm{PS}-\mathrm{AP} \mathrm{P}^{2} \\
& =\mathrm{BP} \cdot \mathrm{PC}-\mathrm{AP}^{2} .
\end{aligned}
$$

(10) In triangle $A B C, A I^{\prime}, A Q$ are isogonals with respect to $A$; through $B$ araw $B E$ parallel to $A P$ meeting $C A$ in $E$; "C "CF " $C A Q \quad, \quad B A, F$; then $E F$ is antiparallel $*$ to $B C$ with respect to $A$.

Figure 35.

For $\angle \mathrm{ABE}=\angle \mathrm{BAP}=\angle \mathrm{CAQ}=\angle \mathrm{ACF}$;

therefore the points $\mathrm{E}, \mathrm{B}, \mathrm{C}, \mathrm{F}$ are concyclic.

The same thing would happen if $\mathrm{BE}, \mathrm{CF}$ were drawn parallel to $A Q, A P$.

(11) In triangle $A B C, A P, A Q$ are isogonal; from $P$ and $Q$ perpendiculars are drawn to $B C$; these perpendiculars are intersected at $D, E$ by a perpendicular to $A B$ at $B$, and at $D^{\prime}, E^{\prime}$ by a perpendicular to $A C$ at $C$. To prove $\dagger$

$\mathrm{BD} \cdot \mathrm{BE}: \mathrm{CD}^{\prime} \mathrm{CE}^{\prime}=\mathrm{AB}^{4}: \mathrm{AC}^{4}$.

* Mr Emile Vigarié.

+ Mr Emile Vigarié in the Journal de Mathématiques Élémentaires, 2nd series, IV. 224 (1885) says that this theorem was communicated to him by his friend $M_{\text {I }}$ Th. Valiech, 


\section{Figure 36.}

Draw $\mathrm{AX}$ perpendicular to $\mathrm{BC}$.

The similar triangles $\mathrm{BDP}, \mathrm{BEQ}, \mathrm{ABX}$ give

$$
\begin{aligned}
& \mathrm{BD}: \mathrm{BP}=\mathrm{AB}: \mathrm{AX} \\
& \mathrm{BE}: \mathrm{BQ}=\mathrm{AB}: \mathrm{AX}
\end{aligned}
$$

therefore

$$
\frac{\mathrm{BD} \cdot \mathrm{BE}}{\mathrm{BP} \cdot \mathrm{BQ}}=\frac{\mathrm{AB}^{2}}{\mathrm{AX}^{2}}
$$

Similarly

$$
\frac{\mathrm{CD}^{\prime} \cdot \mathrm{CE}^{\prime}}{\mathrm{CP} \cdot \mathrm{CQ}}=\frac{\mathrm{AC}^{2}}{\mathrm{AX}^{2}}
$$

therefore

$$
\frac{\mathrm{BD} \cdot \mathrm{BE}}{\mathrm{CD}^{\prime} \cdot \mathrm{CE}^{\prime}} \cdot \frac{\mathrm{CP} \cdot \mathrm{CQ}}{\mathrm{BP} \cdot \mathrm{BQ}}=\frac{\mathrm{AB}^{2}}{\mathrm{AC}^{\prime}}
$$

therefore

$$
\frac{\mathrm{BD} \cdot \mathrm{BE}}{\mathrm{CD}^{\prime} \cdot \mathrm{CE}^{\prime}} \cdot \quad \frac{\mathrm{AC}^{2}}{\mathrm{AB}^{2}}=\frac{\mathrm{AB}^{2}}{\mathrm{AC}^{2}}
$$

(12) If in (11) $A Q$ be the median* from $A$, then

$$
B D: C D^{\prime}=A B^{3}: A C^{3} \text {. }
$$

Figure 36.

For

and

therefore
$\mathrm{BE}: \mathrm{BQ}=\mathrm{AB}: \mathrm{AX}$

$\mathrm{CE}^{\prime}: \mathrm{CQ}=\mathrm{AC}: \mathrm{AX}$

$\mathrm{BE}: \mathrm{CE}^{\prime}=\mathrm{AB}: \mathrm{AC}$,

whence the result follows.

If three straight lines drawn through the vertices of a triangle are concurrent, their isogonals with respect to the angles of the triangle are also concurrent. $\ddagger$

* Mr Emile Vigarié in the Journal de Mathématiques Élémentaircs, 2nd series, IV. 225 (1885).

+ Steiner in Gergonne's Annales, xix. 37-64 (1828), or Steiner's Gesammelte Werke, I. 193 (1831). Ivory in his paper previously cited proves the theorem :

If the isogonals $\mathrm{BO}, \mathrm{BO}^{\prime}$ meet the bisector of $\angle \mathrm{A}$ at $\mathrm{O}, \mathrm{O}^{\prime}$, then $\mathrm{BO}: \mathrm{CO}=\mathrm{BO}^{\prime}: \mathrm{CO}^{\prime}$; and he adds as a corollary that $\mathrm{CO}, \mathrm{CO}^{\prime}$ are isogonals with respect to $\mathrm{C}$. 


\section{Figure 37.}

Let $\mathrm{BO}, \mathrm{BO}^{\prime}$ be isogonals with respect to $\mathrm{B}$

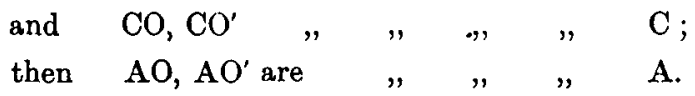

Denote the distances of $O$ from the sides by $p_{1} p_{2} p_{3}$ and those of $\mathrm{O}^{\prime}$ by $q_{1} q_{2} q_{3}$

Then $p_{1} q_{1}=p_{2} q_{2}$ and $p_{1} q_{1}=p_{3} q_{3}$

therefore $p_{2} q_{2}=p_{3} q_{3}$

therefore $\mathrm{AO}, \mathrm{AO}^{\prime}$ are isogonals with respect to $\mathrm{A}$.

Another demonstration will be found in C. Adams's Eigenschaften des...Dreiecks, pp. T-8 (1846).

Points such as $0, \mathrm{O}^{\prime}$ determined by the intersection of pairs of isogonal lines will be called isogonal points, or simply isogonals, with respect to the triangle $A B C$.

They are sometimes* called isogonally conjugate points, or isogonal conjugates, but more frequently on the continent of Europe inverse points with respect to the triangle $\mathrm{ABC}$.

The designation, inverse points, was suggested about the same time in Scotland and in France. See a paper read before the Royal Society of Edinburgh on 20th March 1865, by the Rev. Hugh Martin, and printed in their Transactions, xxiv. 37-52: and an article by Mr J. J. A. Mathieu in the Nouvelles Annales, 2nd series, IV. 393-407, 481-493, 529-537 (1865).

Perhaps the adoption of the nomenclature proposed by $\mathrm{Mr}$ G. de Longchamps in the Journal de Mathématiques Elémentaires, 2nd series, V. 109 (1886) would be advantageous.

$$
\therefore B O C+\angle B O^{\prime} C=180^{\circ}+A \text {. }
$$

Figure 37.

For

$$
\begin{aligned}
\angle \mathrm{BOC} & =\mathrm{A}+\mathrm{ABO}+\mathrm{ACO}, \\
& =\mathrm{A}+\mathrm{CBO}^{\prime}+\mathrm{BCO}^{\prime},
\end{aligned}
$$

and

$$
-\mathrm{BO}^{\prime} \mathrm{C}=\mathrm{A}+\mathrm{ABO}^{\prime}+\mathrm{ACO}^{\prime} ;
$$

therefore

$$
\begin{aligned}
\angle \mathrm{BOC}+\angle \mathrm{BO}^{\prime} \mathrm{C} & =2 \mathrm{~A}+\mathrm{B}+\mathrm{C}, \\
& =180^{\circ}+\mathrm{A} .
\end{aligned}
$$

\footnotetext{
- Professor J. Neuberg's Mémoire sur le Tétraèdre, p. 10 (1884).
} 
(2) In triangle $\mathrm{ABC}, \mathrm{AP}_{1} \mathrm{BP}_{2} \mathrm{CP}_{3}$ are concurrent at $O$, and

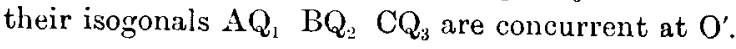

\section{Figure 36.}

Suppose $\mathrm{BP}_{2} \quad \mathrm{BQ}_{2}$ to form one straight line and $\mathrm{CP}_{3} \mathrm{CQ}_{3}, \quad, \quad, \quad, \quad$, ; then the points $O \mathrm{O}^{\prime}$ coincide.*

There are four cases.

(a) If $\mathrm{BP}_{2} \mathrm{CP}_{3}$ bisect the interior angles $\mathrm{B}, \mathrm{C}$, then $\mathrm{AP}_{1}$ bisects the interior angle $\mathrm{A}$.

(b) If $\mathrm{BP}_{2}, \mathrm{CP}_{3}$ bisect the exterior angles $\mathrm{B}, \mathrm{C}$, then $\mathrm{AP}_{1}$ bisects the interior angle $A$.

(c) If $\mathrm{BP}_{2}$ bisects the interior angle $\mathrm{B}$ and $\mathrm{CP}_{3}, "$, exterior , $\mathrm{C}$, then $\mathrm{AP}_{1} \quad, \quad$, exterior , A.

(d) If $\mathrm{BP}_{2}$ bisects the exterior angle $\mathrm{B}$ and $\mathrm{CP}_{3}, "$, interior , $\mathrm{C}$, then $\mathrm{AP}_{1}, \quad$, exterior, $\mathrm{A}$.

Hence the six bisectors of the angles of a triangle meet three by three in four points.

\section{Figure 36.}

(3) By considering $A P_{1} Q_{1}$ as the triangle, and $\mathrm{AB}, \mathrm{AC}$ as the isogonals

\begin{tabular}{|c|c|}
\hline 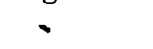 & $\mathrm{BP}_{1} \cdot \mathrm{CP}_{1}: \mathrm{BQ}_{1} \cdot \mathrm{CQ}_{1}=\Delta \mathrm{P}_{1}{ }^{2}: \mathrm{AQ}_{1}{ }^{2}$ \\
\hline Similarly & $\mathrm{CP}_{2} \cdot \mathrm{AP}_{2}: \mathrm{CQ}_{2} \cdot \mathrm{AQ}_{2}=\mathrm{BP}_{2}{ }^{2}: \mathrm{BQ}_{2}{ }^{2}$, \\
\hline & $A P_{3} \cdot \mathrm{BP}_{3}: A Q_{3} \cdot \mathrm{BQ}_{3}=C \mathrm{CP}_{3}{ }^{2}: \mathrm{CQ}_{3}{ }^{2}$ \\
\hline erefore & 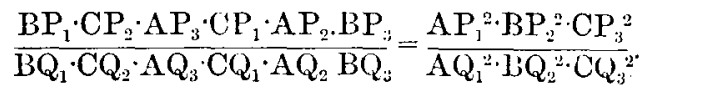 \\
\hline & $\mathrm{BP}_{1} \cdot \mathrm{CP}_{2} \cdot \mathrm{AP}_{3}=\mathrm{CP}_{1} \cdot \mathrm{AP}_{2} \cdot \mathrm{BP}_{3}$ \\
\hline & $\mathrm{BQ}_{1} \cdot \mathrm{CQ}_{2} \cdot \mathrm{AQ}_{3}=\mathrm{CQ}_{1} \cdot \mathrm{AQ}_{2} \cdot \mathrm{BQ}_{3}$ \\
\hline fore & $\frac{\mathrm{AP}_{1} \cdot \mathrm{BP}_{2} \cdot \mathrm{CP}_{3}}{A Q_{1} \cdot \mathrm{BQ}_{2} \cdot \mathrm{CQ}_{3}}=\frac{\mathrm{BP}_{1} \cdot \mathrm{CP}_{2} \cdot A P_{3}}{B Q_{1} \cdot C Q_{2} \cdot A Q_{3}}=\frac{\mathrm{CP}_{1} \cdot \mathrm{AP}_{2} \cdot \mathrm{BP}_{3}}{\mathrm{CQ}_{1} \cdot A Q_{2} \cdot B Q_{3}}$ \\
\hline
\end{tabular}

* C. Adams's Eigenschaften des...Dreiccks, p. s (1846). Adams gives also (3). 
Positions of two isogonal points with reference to a triangle.

(1) Any point on a side has for isogonal point the opposite vertex.

(2) A vertex has for isogonal point any point on the opposite side.

(3) A point inside the triangle has its isogonal point also inside the triangle.

(4) If a point be outside the triangle and situated in the angle vertically opposite to $\angle \mathrm{BAC}$, for example, its isogonal point will be outside the triangle and situated in that segment of the circumcircle (remote from A) cut off by $\mathrm{BC}$.

(5) If a point be outside the circumcircle and situated within the angle $\mathrm{BAC}$, for example, its isogonal point will be outside the circumcircle and situated within the same angle.

(6) If a point be on the circumference of the circumcircle, its isogonal point will be at infinity.

The truth of these statements," which are not quite obvious, may be ascertained by the construction of a few tigures. Of the last statement the following proof may be given :-

\section{Figure 39.}

If $\mathrm{AD}, \mathrm{BE}, \mathrm{CF}$, be three parallel lines drawn through the vertices of a triangle $\mathrm{ABC}$, their three isogonals will be concurrent at a point on the circumference of the circumcircle. $\dagger$

Because $\mathrm{AD}, \mathrm{BE}, \mathrm{CF}$ are parallel, therefore $\operatorname{arc} \mathrm{AE}=\operatorname{arc} \mathrm{BD}$, arc $\mathrm{BC}=\operatorname{arc} \mathrm{EF}$.

Make arc $\mathrm{CP}$ equal to arc $\mathrm{BD}$; join $\mathrm{AP}, \mathrm{BP}, \mathrm{CP}$.

* They are all given by Mr J. J. A. Mathieu in Nouvelles Annales, 2nd series, IV. 403 (1865).

+ Professor Eugenio Beltrami in Memorie del l'Accademia delle Scienze del Istituto di Bologna, 2nd series, II., 383 (1863). 
Since $\operatorname{arc} \mathrm{CP}=\operatorname{arc} \mathrm{BD}$, therefore $\angle \mathrm{CAP}=\angle \mathrm{BAD}$, and $A P$ is isogonal to $A D$.

Since $\operatorname{arc} \mathrm{CP}=\operatorname{arc} \mathrm{AE}$, therefore $\angle \mathrm{CBP}=\angle \mathrm{ABE}$, and $\mathrm{BP}$ is isogonal to $\mathrm{BE}$.

Since arc $\mathrm{BC}=\operatorname{arc} \mathrm{EF}, \operatorname{arc} \mathrm{CP}=\operatorname{arc} \mathrm{AE}$, therefore $\operatorname{arc} \mathrm{BP}=\operatorname{arc} \mathrm{AF}$; therefore $\angle \mathrm{BCP}=\angle \mathrm{ACF}$, and $\mathrm{CP}$ is isogonal to $\mathrm{CF}$.

Hence, if $P$ be a point on the circumcircle of $A B C$, the point isogonal to it is the point of concurrency of $\mathrm{AD}, \mathrm{BE}, \mathrm{CF}$.

(1) AD is perpendicular* to the Wallace line $\mathrm{P}(\mathrm{ABC})$.

This follows from $\$ 1,(3)$.

\section{$\$ 5$.}

If three angular transversals cut the opposite sides in three collinear points, their isogonals will also cut the opposite sides in three collinear points.*

\section{Figure 40.}

Let $\mathrm{AD}, \mathrm{AD}^{\prime} ; \mathrm{BE}, \mathrm{BE}^{\prime}$; $\mathrm{CF}, \mathrm{CF}^{\prime}$ be pairs of isogonals ; then if $\mathrm{D}, \mathrm{E}, \mathrm{F}$, be collinear, so will $\mathrm{D}^{\prime}, \mathrm{E}^{\prime}, \mathrm{F}^{\prime}$.

For

$$
\begin{aligned}
& \frac{\mathrm{BD} \cdot \mathrm{BD}^{\prime}}{\mathrm{CD} \cdot \mathrm{CD}^{\prime}}=\frac{c^{2}}{b^{2}}, \\
& \frac{\mathrm{CE} \cdot \mathrm{CE}^{\prime}}{\mathrm{AE} \cdot \mathrm{AE}^{\prime}}=\frac{u^{2}}{c^{2}}, \\
& \frac{\mathrm{AF} \cdot \mathrm{AF}^{\prime}}{\mathrm{BF} \cdot \mathrm{BF}^{\prime}}=\frac{b^{2}}{a^{2}} ;
\end{aligned}
$$

therefore $\frac{\mathrm{BD} \cdot \mathrm{CE} \cdot \mathrm{AF}}{\mathrm{CD} \cdot \mathrm{AE} \cdot \mathrm{BF}} \cdot \frac{\mathrm{BD}^{\prime} \cdot \mathrm{CE}^{\prime} \cdot \mathrm{AF}^{\prime}}{\mathrm{CD}^{\prime} \cdot \mathrm{AE}^{\prime} \cdot \mathrm{BF}^{\prime}}=1$.

* Professor J. Neuherg in Rouché and Comberousse's Traité de Géometrié, First Part, p. 439 (1891).

+ Townsend's Modern Geometry, I. 181 (1863). 


$\begin{array}{ll}\text { Now } & \frac{\mathrm{BD} \cdot \mathrm{CE} \cdot \mathrm{AF}}{\mathrm{CD} \cdot \mathrm{AE} \cdot \mathrm{BF}}=1 ; \\ \text { therefore } & \frac{\mathrm{BD}^{\prime} \cdot \mathrm{CE}^{\prime} \cdot \mathrm{AF}^{\prime}}{\mathrm{CD}^{\prime} \cdot \mathrm{AE^{ \prime }} \cdot \mathrm{BF}^{\prime}}=1 ;\end{array}$

therefore $\mathrm{D}^{\prime}, \mathrm{E}^{\prime}, \mathrm{F}^{\prime}$ are collinear.

$\S 6$.

If $O$ be any point in the plane of triangle $A B C$, and $A O B O C O$ meet the circumcircle in $A_{1} B_{1} C_{1}$ and $D E E$ be the projections of $O$ on $B C C A A B$ the triangles $A_{1} B_{1} C_{1} D E F$ are directly similar, and the point $O$ of triangle $D E F$ corresponds to that point of $A_{1} B_{1} C_{1}$ which is isogonal* to $O$.

\section{Fugure 41.}

For the points O F B D are concyclic;

$$
\begin{aligned}
& \text { therefore } \quad \angle F D O=\angle F B O \\
& =\angle B_{1} A_{1} Q \text {. } \\
& \text { Sinilarly } \quad \angle \mathrm{EDO}=\angle \mathrm{C}_{1} \mathrm{~A}_{1} \mathrm{O} \text {. }
\end{aligned}
$$

The demonstration may be easily seen to apply to the more general case where $A_{1} B_{1} C_{1}$ are taken inverse to $O$ with any other constant of inversion.*

(1) If $O$ be the orthocentre of $\mathrm{ABC}$, it must be the incentre or an excentre of DEF, and therefore the incentre or an excentre of $A_{1} B_{1} C_{1}$.

(2) If $\mathrm{O}$ be the circumcentre of $\mathrm{ABC}$, it must be the orthocentre of DEF, and therefore the circumcentre of $A_{1} B_{1} C_{1}$.

(3) If $O$ be the incentre of $A B C$, it must be the circumcentre of $\mathrm{DEF}$, and therefore the orthocentre of $\mathrm{A}_{1} \mathrm{~B}_{1} \mathrm{C}_{1}$.

(4) If $O$ be an excentre of $A B C$, it must be the circumcentre of $D E F$, and therefore the orthocentre of $A_{1} B_{1} C_{1}$.

* Mr E. M. Langley and Professor Neuberg. (1)-(4) are Mr Langley's. See the Seventeenth General Report of the Association for the Improrement of Geometrical Teaching, p. 45 (1891.) 
If tuo points be isoyonal with respect to a triangle their six projections on the sides of the triangle are concyclic.*

\section{Figure 42.}

Let $\mathrm{O}, \mathrm{O}^{\prime}$ be isogonal with respect to $\mathrm{ABC}$, and let $\mathrm{D}, \mathrm{E}, \mathrm{F}$, $\mathrm{D}^{\prime}, \mathrm{E}^{\prime}, \mathrm{F}^{\prime}$ be their projections on the sicles $\mathrm{BC}, \mathrm{CA}, \mathrm{AB}$.

Then EF is antiparallel to $\mathrm{E}^{\prime} \mathrm{F}^{\prime}$ with respect to $\mathrm{A}$;

therefore

$\mathrm{E}, \mathrm{E}^{\prime} \mathrm{F}, \mathrm{E}^{\prime}$, are concyclic.

Similarly

and

$\mathrm{F}, \mathrm{F}^{\prime} \mathrm{D}, \mathrm{D}^{\prime}, \quad, \quad, \quad$,

$\mathrm{D}, \mathrm{D}^{\prime} \mathrm{E}, \mathrm{E}^{\prime} \quad, \quad, \quad$;

therefore the six points are concyclic.

$\$ 8$

If $O O^{\prime}$ be isogonal points with respect to $A B C$, and $D E F$ $D^{\prime} E^{\prime} F^{\prime \prime}$ be their respective projections on $I B C C A A B$, then

$A O B O C O$ are perpendicular to the sides of $D^{\prime} E^{\prime \prime} F^{\prime \prime}$

$A O \mathrm{HO}^{\prime} \mathrm{CO} \quad, \quad, \quad, \quad D E \mathrm{~F}^{\prime}$.

\section{Figure 42 .}

This has been established in $\$ 1,(3)$.

The application of the preceding properties of isogonals to the particular case of medians and symmedians will be taken up in a succeeding paper.

* Steiner in Gergonne's Annales, xix. 37-64 (1828).

In the same article will be found also the property of $\$ 8$. 